\title{
NEGÓCIO JURÍDICO PROCESSUAL EM SEDE DE EXECUÇÃO FISCAL DE CRÉDITOS TRIBUTÁRIOS COMO FORMA DE ACESSO À JUSTIÇA ${ }^{1}$
}

\section{PROCESSUAL LEGAL BUSINESSES IN THE FISCAL EXECUTION OF TAX CREDITS AS A FORM OF ACCESS TO JUSTICE}

Gabriela Machado Rennó Mestranda em Direito e Políticas Públicas pela Universidade Federal de Goiás. Pós-Graduanda em Direito Tributário pela Universidade de São Paulo. Bacharela em Direito pela Universidade Federal de Goiás. Artigo vinculado a projeto de pesquisa desenvolvida no Programa de Pós-graduação em Direito e Políticas Públicas - PPGDP, nível Mestrado Profissional, da Universidade Federal de Goiás. Advogada. Brasília/DF. E-mail: gabriela.renno@hotmail.com.

Silzia Alves Carvalho Doutora em Direito pela Pontifícia Universidade Católica de São Paulo, Mestre em Direito pela Pontifícia Universidade Católica de São Paulo. Realiza estágio pós-doutoral na Universidade de Coimbra em Ciências Jurídico-Filosóficas. Professora em regime de dedicação exclusiva de Direito Processual Civil na Faculdade de Direito da Universidade Federal de Goiás; e pesquisadora junto ao Programa de Pósgraduação em Direito e Políticas Públicas - PPGDP, nível Mestrado Profissional, da Universidade Federal de Goiás, a respeito das políticas públicas de acesso à justiça e consensualidade. Goiânia/GO.

E-mail:

silzia_carvalho@ufg.br.

\footnotetext{
${ }^{1}$ Artigo recebido em 18/02/2021 e aprovado em 28/06/2021.
} 
RESUMO: A relação antagônica entre fisco e contribuinte estabelece barreiras que, além de gerar colapso no Poder Judiciário com congestionamento processual, não resulta em efetiva arrecadação e, por consequência, não representa efetivo acesso à justiça. Ante a morosidade sistêmica das execuções fiscais, bem como a imprescindibilidade de posturas do direito público consensual, compreende-se a consensualidade como forma de promover a pacificação. Nessa linha, o presente artigo objetiva instigar reflexões sobre o Negócio Jurídico Processual em sede de execução fiscal como forma de efetivo acesso à justiça, na medida em que tal procedimento é um mecanismo consensual que objetiva à arrecadação fiscal.

PALAVRAS-CHAVE: Administração Pública. Consensualidade. Execução fiscal. Negócios jurídicos processuais. Acesso à Justiça.

ABSTRACT: The antagonistic relationship between tax authorities and taxpayers establishes barriers that, in addition to causing the Judiciary to collapse with procedural congestion, do not result in effective collection and, consequently, do not represent effective access to justice. Given the systemic slowness of tax foreclosures, as well as the need for consensual public law stances, consensuality is understood as a way to promote pacification. Along this line, this article aims to instigate reflections on the Procedural Legal Business in terms of tax enforcement as a means of effective access to justice, as this procedure is a consensual mechanism aimed at tax collection.

KEYWORDS: Public Administration. Consensuality. Tax enforcement. Procedural legal affairs. Access to justice.

SUMÁRIO: Introdução - $1 \mathrm{O}$ procedimento como forma de acesso à justiça -2 Consensualidade em âmbito tributário - 3 Morosidade sistêmica das execuções fiscais - 4 Instrumentalização do artigo 190 do CPC em sede de execução fiscal - Considerações finais - Referências. 


\section{INTRODUÇÃO}

Nos últimos anos, os relatórios Justiça em Números, do Conselho Nacional de Justiça (CNJ), revelam que as execuções fiscais são as principais responsáveis pela morosidade no Poder Judiciário² ${ }^{2}$

Nesse cenário, a ineficiência da utilização da lei de execução fiscal como instrumento tradicional para satisfação de dívidas fiscais é atestada pela alta taxa de congestionamento de execuções fiscais perante o Poder Judiciário.

Destarte, ciente de que a crise econômica que assola o Brasil enseja maior diálogo sobre a arrecadação fiscal, o presente estudo visa fomentar discussão acerca da construção de um sistema tributário consensual, com o objetivo de estimular reflexões quanto à arrecadação tributária por meio de atuação negocial da administração tributária na gestão dos créditos inscritos em dívida ativa.

Após reflexões sobre a consensualidade em âmbito tributário, o artigo realça o avanço no tema, de forma específica, a partir da instrumentalização do Negócio Jurídico Processual (NJP) pela Procuradoria Geral da Fazenda Nacional, pioneira no país em relação à utilização da consensualidade tributária como forma de arrecadar recursos aos cofres públicos.

A temática será abordada a partir das concepções de processo e procedimento como forma de acesso à justiça, com base nas lições de Ada Pellegrini e na noção de acesso à justiça como sendo a concretização da decisão de mérito em tempo razoável e por meios adequados, conforme preceituam Mauro Cappelletti e Boaventura Santos ${ }^{3}$.

Em relação à metodologia, utiliza-se a abordagem hipotético-dedutiva, bem como procedimentos de análise bibliográfica e documental. Informa-se que para a obtenção dos dados acerca dos negócios jurídicos já firmados em âmbito federal, utilizou-se do procedimento previsto na Lei de Acesso à Informação $n^{\circ} 12.527 / 2011^{4}$. Outrossim, quanto aos dados obtidos para análise jurídica do cenário da execução fiscal no país, o presente

\footnotetext{
2 Justiça em Números 2020; ano-base 2019/Conselho Nacional de Justiça - Brasília: CNJ, 2020, p. 150.

${ }^{3}$ Convém citar, nesse toar, que no caso das execuções fiscais o tempo médio de duração processual é de oito anos, o que demonstra que não há efetivo acesso à justiça quando se trata de interesses coletivos de arrecadação tributária em sede judicial (Justiça em Números 2020; ano-base 2019/Conselho Nacional de Justiça - Brasília: CNJ, 2020, p. 161.).

${ }^{4}$ Processo de solicitação de informação à PGFN registrado sob o nº 03005.183995/2020-35.
} 
estudo utilizou relatórios Justiça em Números do CNJ, Relatório PGFN em Números 2020 e o estudo do IPEA ${ }^{5}$ sobre gestão e jurisdição da execução fiscal da União.

Em síntese, o presente artigo visa empreender esforços na compreensão da consensualidade como dever de atuação gerencial da administração tributária, a partir da concepção de que a consensualidade, em especial por meio dos negócios jurídicos processuais, é uma forma de pacificação, arrecadação tributária e consequente acesso à justiça.

\section{O PROCEDIMENTO COMO FORMA DE ACESSO À JUSTIÇA}

Não se pode olvidar que o diálogo entre as partes é necessário para uma decisão dialogal, legítima e justa ${ }^{6}$. O procedimento mais completo para a pacificação é a justiça conciliativa por meio do diálogo, oportunidade em que as partes constroem o consenso.

Parte-se do pressuposto ensinado por Ada Pellegrini ${ }^{7}$ de que o procedimento é tudo quanto o processo necessita para atingir seus objetivos e também pode resolver conflitos e ser pacificador. A Autora assevera que o enfoque do processo que tem como finalidade jurídica a atuação do direito material é instrumento em relação a este.

Processo e procedimento, portanto, estão no mesmo plano de realizar jurisdição, ou seja, pacificar com justiça. Nesse sentido, a principal meta do acesso à justiça, ou melhor, a uma ordem jurídica justa, é a pacificação social.

Mauro Cappelletti ensina que uma das formas de possibilitar o acesso à justiça seria a utilização de meios alternativos de resolução de conflitos. Para o autor, é necessário efetivar as práticas inovadoras que fomentem o acesso à justiça, o que interessa a todos os indivíduos ${ }^{8}$.

No âmbito das execuções fiscais, por sua vez, o acesso à justiça se substancia na efetiva resolução processual e consequente arrecadação de tributos. Sendo assim, o sistema

\footnotetext{
${ }^{5}$ BRASIL. Instituto de Pesquisa Econômica Aplicada (IPEA). Comunicado do IPEA $n^{\circ} 127$. Disponível em: http://www.ipea.gov.br/portal/index.php?opition=-com_content\&view=article\&id=12794. Acesso em: 25 ago. 2020.

${ }^{6}$ GRINOVER, Ada Pellegrin. Ensaio sobre a processualidade: fundamentos para uma nova teoria geral do processo. Brasília: Gazeta Jurídica, 2016, p. 23.

${ }^{7}$ GRINOVER, Ada Pellegrin. Ensaio sobre a processualidade: fundamentos para uma nova teoria geral do processo. Brasília: Gazeta Jurídica, 2016, p. 17.

${ }^{8}$ CAPPELLETTI, M.; GARTH, B. Acesso à justiça. Tradução Ellen Gracie Northfleet. Porto Alegre: Frabis, 1988 , p. 87.
} 
tributário deve ser pautado pela eficiência e justiça simultaneamente, o que remonta à necessidade de buscar alternativas não conflituosas e de sinergia.

Nesse sentido, o conceito de acesso à justiça é de difícil definição, mas deve ser compreendido para além da garantia constitucional de direito à ação ou acesso aos órgãos jurisdicionais. Para Kazuo Watanabe, o acesso à justiça é efetivo quando há uma decisão de mérito em tempo razoável, ou, ainda, por meios considerados adequados. Kazuo Watanabe ${ }^{9}$ assevera que se deve viabilizar o acesso à ordem jurídica justa, mais do que o acesso à justiça.

Considerando a área tributária, apreende-se dos relatórios anuais do $\mathrm{CNJ}$ que a Fazenda Pública é a maior litigante do país. Assim, organizar meios alternativos de solução de conflitos é uma obrigação do Estado e não uma faculdade. Importante considerar também que a negociação como meio para a solução pacífica de controvérsias é uma obrigação de conduta e não de resultado.

Com efeito, na justiça conciliativa não há exercício do poder em consonância ao antigo modelo burocrático já superado no século XX, uma vez que se deve garantir o acesso à justiça pelo exercício de função e atividade respeitadas pelo corpo social para a solução de conflitos.

Em tal contexto, considera-se a tutela processual adequada quando há intermédio do procedimento adequado. De modo que o procedimento assume uma nova dimensão, sendo, ao lado do processo, instrumento para o atingimento da pacificação.

No caso do Negócio Jurídico Processual, trata-se de instrumento para o atingimento da arrecadação fiscal, assumindo nova dimensão de satisfação da tutela processual, inclusive, de forma a acompanhar o fomento ao desenvolvimento de métodos consensuais como forma de resolução de conflitos no ordenamento jurídico brasileiro, por meio de políticas públicas destinadas à efetivação do acesso à justiça, conforme a Resolução $\mathrm{n}^{\circ}$ 125/2010 do Conselho Nacional de Justiça.

Urge destacar que jurisdição é a garantia de acesso à justiça para solução de conflitos, utilizando processo e procedimento. Nesse esteio, Ada Pellegrini entende que justiça consensual integra o conceito de acesso à justiça e ressalta especialmente quanto ao

\footnotetext{
${ }^{9}$ WATANABE, Kazuo. Política Pública do Poder Judiciário Nacional para tratamento adequado dos conflitos de interesses. Revista de Processo (RePro), São Paulo, ano 136, v. 195, maio 2011, p. 383.
} 
NJP que o sistema processual admite que o juiz e as partes possam introduzir alterações no procedimento, o qual também pode resolver conflitos e ser pacificador ${ }^{10}$.

No âmbito tributário, as possibilidades abarcadas pelo NJP possibilitam até mesmo a finalização da lide tributária com a arrecadação final do crédito, por meio de planos de amortização.

Assim, os negócios jurídicos processuais permitem estipular mudanças no procedimento para ajustá-lo às especificidades da causa. Além disso, são pautados na consensualidade e na convencionalidade, destinados a regulamentar as regras o jogo, de natureza processual.

Cumpre destacar que a cooperação é dever essencial dos sujeitos do processo, para obter, em tempo razoável, decisão de mérito justa e efetiva, conforme estipula o artigo $6^{\circ}$ do $\mathrm{CPC}^{11}$.

Em âmbito fiscal, implica dizer que o fisco deve abdicar da superioridade anteriormente enraizada com a administração burocrática que previa o administrador acima do administrado, para colocar-se em posição de igualdade negocial ao contribuinte, visando atingir a finalidade do processo, qual seja, o fim da lide e a arrecadação fiscal necessária.

Há ainda que se observar o ensinado por Ada Pellegrini ${ }^{12}$ que, para o controle jurisdicional de políticas públicas ser justo, equilibrado e exequível, é necessário instituir um processo adequado à solução dos conflitos de interesse público (como a arrecadação tributária): o processo estrutural. Tal tipo de processo visa abranger a percepção de tutela adequada a cada tipo de conflito. Assim, a leitura do princípio constitucional de acesso à justiça (Artigo $5^{\circ}$, inciso XXXV da Constituição Federal ${ }^{13}$ ) é compreendida a partir de meios consensuais de exercício jurisdicional.

\footnotetext{
${ }^{10}$ GRINOVER, Ada Pellegrin. Ensaio sobre a processualidade: fundamentos para uma nova teoria geral do processo. Brasília: Gazeta Jurídica, 2016, p. 18.

11 Art. $6^{\circ}$ Todos os sujeitos do processo devem cooperar entre si para que se obtenha, em tempo razoável, decisão de mérito justa e efetiva.

${ }^{12}$ GRINOVER, Ada Pellegrin. Ensaio sobre a processualidade: fundamentos para uma nova teoria geral do processo. Brasília: Gazeta Jurídica, 2016, p. 42.

${ }^{13} \mathrm{Art.} 5^{\circ}$ Todos são iguais perante a lei, sem distinção de qualquer natureza, garantindo-se aos brasileiros e aos estrangeiros residentes no País a inviolabilidade do direito à vida, à liberdade, à igualdade, à segurança e à propriedade, nos termos seguintes: XXXV - a lei não excluirá da apreciação do Poder Judiciário lesão ou ameaça a direito.
} 
Desta maneira, destaca-se que na negociação as partes envolvidas chegam à solução quando possuem bom relacionamento e conseguem tratar objetivamente das questões a serem decididas ${ }^{14}$, aspecto desafiador na relação antagônica entre fisco e contribuinte.

\section{A CONSENSUALIDADE EM ÂMBITO TRIBUTÁRIO}

O ambiente atual de consensualidade tributária é permeado pela consensualidade prevista no Código de Processo Civil de 2015, com vistas a finalizar os litígios e estabelecer concessões mútuas. Desse modo, o NJP, previsto no artigo 190 do CPC, não é um meio alternativo de resolução de conflitos, mas, sim, um procedimento de processo que visa ao diálogo e à aproximação entre polos opostos para resolver o litígio firmado.

Não obstante, aplicar o artigo 190 do CPC $^{15}$ em âmbito fiscal é uma forma de resguardar o interesse público como meio de aproximação de polos inversos, em prol do interesse público da arrecadação tributária - além de ser uma forma de prestação jurisdicional, tendo em vista que a execução fiscal representa enorme problema no Poder Judiciário.

Convém consignar que a concepção de interesse público acompanhou a evolução da Administração Pública, em notória passagem do modelo burocrático ao modelo gerencial, abandonando o caráter absoluto e dogmático do conceito, em prol de diálogos abertos em um modelo de administração gerencial.

Nesse cenário, a Constituição Federal de 1988 optou por um modelo de Estado Social, intervencionista e redutor de desigualdades. No caso tributário, portanto, entende-se que, aplicar qualquer esforço em prol da arrecadação aos cofres públicos é a melhor forma de vangloriar recursos e, por conseguinte, promover o bem comum de forma máxima, considerando a baixa probabilidade de recuperação dos créditos inscritos em dívida ativa e

\footnotetext{
${ }^{14}$ GRINOVER, Ada Pellegrin. Ensaio sobre a processualidade: fundamentos para uma nova teoria geral do processo. Brasília: Gazeta Jurídica, 2016, p. 67.

15 Art. 190. Versando o processo sobre direitos que admitam autocomposição, é lícito às partes plenamente capazes estipular mudanças no procedimento para ajustá-lo às especificidades da causa e convencionar sobre os seus ônus, poderes, faculdades e deveres processuais, antes ou durante o processo.

Parágrafo único. De ofício ou a requerimento, o juiz controlará a validade das convenções previstas neste artigo, recusando-lhes aplicação somente nos casos de nulidade ou de inserção abusiva em contrato de adesão ou em que alguma parte se encontre em manifesta situação de vulnerabilidade.
} 
a necessidade de arrecadação de recursos que poderão fundamentar políticas públicas relevantes.

Posto isso, diante da relevância de intensificar esforços voltados ao aumento da arrecadação e ciente de que o futuro da execução fiscal depende de medidas que otimizem o processo, o NJP figura-se como uma das propostas alternativas complementares à solução da questão creditória fiscal.

Trata-se, pois, de dever de atuação da boa administração pública e não de privilégio concedido ao contribuinte. Gustavo Binenbojm ${ }^{16}$ assevera que "em muitos casos, na busca da promoção do melhor interesse público, a Administração deve despir-se de sua potestade para buscar consensos; deve reconhecer que a lógica da autoridade nem sempre é o meio mais eficiente de apuração do interesse público".

Nesse viés, tem-se que a eficiência administrativa deve ser um dos pilares da Política Pública tributária nacional e, sob essa óptica, a consensualidade em âmbito tributário torna-se possível remédio no combate da patologia da litigância tributária.

Moreira Neto aduz que a consensualidade estimula a criação de soluções privadas de interesse público ${ }^{17}$. Assim, a reforma e a modernização do Estado e da Administração Pública valoriza o direito do cidadão e incentiva a sua participação, tendo em vista que o modelo de administração não é mais pautado pela autoridade, mas sim pela promoção de direitos fundamentais.

Insta destacar que a negociação é considerada um meio adequado à resolução de conflitos, sendo parte do sistema multiportas. A expressão multiportas decorre de uma metáfora, ou seja, com várias possibilidades de portas, a depender do problema apresentado, há a devida solução por um dos meios adequados, seja a mediação, conciliação, arbitragem ou a própria justiça estatal. ${ }^{18}$

Nesse contexto, há a concepção de "colaborative law" como uma mediação sem mediador, sendo, inclusive, uma forma de suprir lacuna dos meios de solução de conflitos,

\footnotetext{
${ }^{16}$ BINENBOJM, Gustavo. A consensualidade administrativa como técnica juridicamente adequada de gestão eficiente de interesses sociais. Revista Eletrônica da Procuradoria Geral do Estado do Rio de Janeiro - PGERJ, Rio de Janeiro, v. 3 n. 3, set./dez. 2020, p. 2.

${ }^{17}$ MOREIRA NETO, Diogo de Figueiredo. Novos institutos consensuais da ação administrativa. Revista de Direito Administrativo, Rio de Janeiro, v. 231, jan. 2003, p. 156.

${ }^{18}$ CABRAL, Antônio do passo; CUNHA, Leonardo Carneiro da. Negociação Direta ou resolução colaborativa de disputas (Collaborative Law): "mediação sem mediador". In: Justiça Multiportas: mediação, conciliação, arbitragem e outros meios de solução adequada para conflitos. Ed. Juspodvim, Salvador, 2016, p. 02.
} 
por permitir alteração de procedimentos para a solução amistosa do conflito. Utiliza-se métodos, originalmente estadunidenses, de negociação colaborativa entre as partes e $\operatorname{advogados}^{19}$.

Os novos métodos de acesso à justiça, aliados às transformações do direito administrativo, fomentam um modelo de Administração Pública garantidora de direitos fundamentais. A consensualidade, por sua vez, passou a ser incorporada na rotina estatal, de modo que alguns autores denominaram se tratar de uma "fuga para o Direito Privado" em busca da eficiência administrativa.

No marco do processo colaborativo, revigorar acordos processuais representa incentivar as partes e advogados para a resolução dos conflitos, como mecanismos de resolução de controvérsias dentro da própria sociedade ${ }^{20}$. Na seara tributária, a participação dos contribuintes é resultado da abertura do diálogo e também da busca pela realização efetiva das garantias individuais e coletivas, dado que a busca pela consensualidade.

Com efeito, a nova e dialógica Administração Tributária tem o condão não só de fomentar a cultura da consensualidade estatal, mas também de propiciar a devida arrecadação tributária de receitas públicas ${ }^{21}$. Os negócios processuais, portanto, são uma forma de maximizar os efeitos do princípio da adequação de procedimentos.

Nota-se, a partir das concepções de diálogo, consensualidade e eficiência, que a Administração Tributária possui a responsabilidade de alcançar uma arrecadação e uma gestão tributária pautada na economicidade e na consensualidade. A atuação racional e eficiente do Judiciário, dessa forma, reflete a boa administração pública. De igual modo, fazse necessário diálogo efetivo para identificar soluções para os problemas tributários postos, mediante concessões processuais.

Diante disso, os novos paradigmas para o direito público conduzem à aproximação entre administrado e administrador, considerando que a consensualidade é um motor da racionalização dos métodos de cobrança tributária, em prol da eficiência. Busca-se, portanto,

\footnotetext{
${ }^{19}$ CABRAL, Antônio do passo; CUNHA, Leonardo Carneiro da. Negociação Direta ou resolução colaborativa de disputas (Collaborative Law): "mediação sem mediador". In: Justiça Multiportas: mediação, conciliação, arbitragem e outros meios de solução adequada para conflitos. Ed. Juspodvim, Salvador, 2016, p. 05.

${ }^{20}$ CABRAL, Antônio do Passo. Convenções processuais. Salvador: JusPodivm, 2020, p. 215.

${ }^{21}$ BACELLAR FILHO, Romeu Felipe. Parecer Administração Tributária. In: Análise dos dispositivos constitucionais da nova Administração tributária. Brasília: Fenafisco, 2008, p. 92.
} 
resultados que melhor reflitam a finalidade do sistema multiportas de alcance do crédito público, ou seja, a melhor satisfação possível, entre os inúmeros obstáculos encontrados.

Convém aduzir, conforme relata Lila Spadoni ${ }^{22}$, que há fatores para que procedimentos justos sejam estabelecidos, como a participação das partes e a neutralidade do juiz. Tais fatores remontam a necessidade de desburocratizar a justiça, para que esta seja mais relacional, em busca da eficácia de medidas que recuperem recursos ao erário.

Fernanda Bourges ${ }^{23}$ aduz, nesse sentido, que não satisfaz o interesse público o envolvimento do Poder Público em demandas judiciais infindáveis, que necessitam de recursos e tempo, uma vez que a existência de tais ações se baseia na realização dos interesses dos cidadãos.

Aliás, a atuação consensual é uma solução pragmática voltada à obtenção dos melhores resultados práticos possíveis, ao mesmo tempo que coloca o Estado em uma posição mais dialógica e democrática na consecução de suas finalidades institucionais ${ }^{24}$. Outrossim, a persecução do crédito público não necessariamente significa a persecução em juízo, sendo cabíveis adoções de outras técnicas resolutivas ${ }^{25}$.

A mudança do enfoque da Administração Pública para a busca da melhor satisfação possível do crédito tributário, portanto, é um postulado para que se estabeleça o dever de consensualidade em âmbito tributário.

\section{MOROSIDADE SISTÊMICA DAS EXECUÇÕES FISCAIS}

O Judiciário Brasileiro se revela assoberbado de execuções fiscais, que são as maiores responsáveis pelo número de feitos em trâmite no Poder Judiciário. Tal fato remonta a necessidade de utilização de mecanismos consensuais entre fisco e contribuinte para movimentar créditos, a exemplo do Negócio Jurídico Processual, abarcado pelo CPC de

\footnotetext{
${ }^{22}$ SPADONI, Lila. Psicologia realmente aplicada ao direito. 2. ed. São Paulo: LTr, 2016, 42-44.

${ }^{23}$ BOURGES, Fernanda Schuhli. Administração Pública dialógica: em busca da concretização isonômica de direitos fundamentais sociais. Revista Eurolatinoamericana de Derecho Administrativo, Santa Fe, v. 5, n. 1, p. 29-53, jan./jun. 2018, p. 46.

${ }^{24}$ BINENBOJM, Gustado. A consensualidade administrativa como técnica juridicamente adequada de gestão eficiente de interesses sociais. Revista Eletrônica da Procuradoria Geral do Estado do Rio de Janeiro - PGERJ, Rio de Janeiro, v. 3 n. 3, set./dez. 2020, p. 7.

${ }^{25}$ AVELINO, Murilo Teixeira. A regulação dos negócios jurídicos processuais pela Fazenda Nacional. Civil Procedure Review, v. 11, n. 2: mai.-ago. 2020, p. 160.
} 
2015 e implementado formalmente em âmbito federal em 2018 pelas pioneiras Portarias $n^{\circ}$ 360/2018 e n ${ }^{\circ}$ 742/2018 da Procuradoria Geral da Fazenda Nacional (PGFN).

Boaventura Santos ${ }^{26}$, ao abordar o tema de reformas processuais e de morosidade, aduz que um dos vetores que levariam à necessária transformação da cultura judiciária são os novos mecanismos de acesso à justiça. Para o autor, no plano dos interesses econômicos é necessário que o sistema judiciário seja eficiente, rápido e que possibilite a previsibilidade nos negócios, a segurança jurídica e a salvaguarda dos direitos de propriedade.

Nota-se ainda maior relevância de tais atributos quando o assunto são os interesses econômicos fazendários, tendo em vista a relevância da arrecadação tributária perante a sociedade, embasada no interesse público de arrecadação fiscal.

Ademais, Boaventura $\operatorname{Santos}^{27}$ assevera que a sociedade reclama por um sistema judiciário que permita a criação de uma cultura jurídica e judiciária que, ao invés de buscar o acesso a algo que já existe, busque a eficiência por meios que sejam vetores de diminuição da morosidade sistêmica e ativa existente nos tribunais espalhados pelo país.

No caso da execução fiscal, tratamos da morosidade sistêmica, que decorre da sobrecarga de trabalho, do excesso de burocracia, de positivismo e de legalismos. Há também morosidade ativa, que ocorre quando operadores concretos e terceiros interpõem obstáculos para impedir que a sequência normal dos procedimentos desfeche o caso.

Não obstante, o acesso à justiça no caso das execuções fiscais abarca a defesa de interesses coletivos, qual seja, de arrecadação tributária que fomentará outras políticas públicas, por meio dos meios alternativos para a resolução de conflitos. Vislumbra-se, assim, a negociação com o contribuinte, utilizando do artigo 190 do Código de Processo Civil, como um instrumento de política pública que auxilie a recuperação de crédito fiscal.

A morosidade ocasiona não só a falta de confiança nos tribunais que são carregados por dívidas antigas com pouca chance de êxito, como também o aumento de gasto público com medidas burocráticas e legais, seguindo o rito da Lei 6.830/90, que não demonstram êxito no deslinde final do processo.

\footnotetext{
${ }^{26}$ SANTOS, Boaventura de Sousa. Para uma revolução democrática da justiça. 3. ed. São Paulo: Cortez, 2011, p. 25.

${ }^{27}$ SANTOS, Boaventura de Sousa. Para uma revolução democrática da justiça. 3. ed. São Paulo: Cortez, 2011, p. 24.
} 
São múltiplos os impactos negativos da morosidade judicial nos objetivos a serem cumpridos pelos tribunais, dado que a morosidade é um problema estrutural que abala a confiança das partes nos tribunais como meio de resolução de conflitos. Tal aspecto remonta a necessidade de fomento à busca consensual de persecução ao crédito tributário, com novos métodos de cooperação.

Nesse esteio, é importante ter em mente os dados que apontam para a necessidade de fomento a técnicas alternativas de resolução de conflito no âmbito fiscal brasileiro. $\mathrm{O}$ IPEA revelou que um processo de execução fiscal na Justiça Federal leva em média oito anos, dois meses e nove dias ${ }^{28}$. E se ocorressem todas as etapas da execução fiscal, o tempo ainda seria maior, quase 16 anos.

Além disso, o Conselho Nacional de Justiça confirma a percepção de morosidade das execuções fiscais, pois, no relatório Justiça em Números, edição 2020, foi demonstrado que a Execução fiscal possui a segunda maior taxa de congestionamento judicial, atrás apenas da execução penal privativa de liberdade.

Os processos de execução fiscal representam 39\% do total de casos pendentes e $70 \%$ das execuções pendentes no Poder Judiciário, com taxa de congestionamento de $87 \%$. Em outras palavras, de cada cem processos de execução fiscal que tramitaram no ano de 2019, apenas 13 foram baixados.

O relatório revela, ademais, que o maior impacto das execuções fiscais está na Justiça Estadual, que concentra $85 \%$ dos processos. No Tribunal de Justiça de Goiás, por exemplo, no ano de 2019, os processos de execução fiscal representaram aproximadamente $39 \%$ de casos pendentes, com taxa de congestionamento de $90 \%{ }^{29}$.

Além da morosidade, a forma de arrecadação também precisa ser debatida, tendo em vista a patente ineficiência arrecadatória do rito legal da execução fiscal. É válido trazer à baila que em estudo divulgado pela Procuradoria Geral da Fazenda Nacional, por meio do PGFN em Números, edição 2020, demonstrou-se que durante o ano de 2019 recuperou-se via cobrança judicial $29,15 \%$ do valor total de $\mathrm{R} \$ 24,4$ bilhões recuperados no ano, o que

\footnotetext{
${ }^{28}$ BRASIL. Instituto de Pesquisa Econômica Aplicada (IPEA). Gestão e jurisdição: o caso da execução fiscal da União. Organizadores: Alexandre dos Santos Cunha, Paulo Eduardo Alves da Silva. - Brasília: Ipea, 2013, p. 278.

${ }^{29}$ Justiça em Números 2020; ano-base 2019/Conselho Nacional de Justiça - Brasília: CNJ, 2020, p. 131.
} 
representa apenas $1 \%$ do valor total inscrito em dívida ativa em 2019 , qual seja, $\mathrm{R} \$ 2,4$ trilhões ${ }^{30}$.

Outrossim, o IPEA demonstrou que o processo de execução se prolonga no tempo, muitas vezes prescrevendo sem qualquer recuperação de crédito, e gera, em média, para a União, o custo de $\mathrm{R} \$ 4.368,00$ (quatro mil, trezentos e sessenta e oito reais) por ação, sem contabilizar gastos com a atividade do próprio exequente.

Os problemas acima relatados demonstram que em sociedades complexas as vias unilaterais de resolução de conflitos já não são satisfatórias, fato que remonta a necessidade de busca por soluções mais céleres nas demandas contra a Fazenda Pública nas questões de recuperação dos créditos fiscais.

Como já adiantado, o Código de Processo Civil mostra sinais de notório incentivo a meios alternativos ao tratar, por exemplo, do já citado Negócio Jurídico Processual. Convém observar, nessa perspectiva, que o Negócio Jurídico Processual, previsto pela PGFN em dezembro de 2018, possibilitou avanço significativo em 2019 na recuperação dos créditos tributários, visto que possibilitou a regularização de cerca de 2,7 bilhões de reais ${ }^{31}$, conforme dados constantes no referido relatório.

A título ilustrativo, cita-se relevante negócio jurídico processual firmado no REsp 1.345.613/SC, após mais de dez anos de discussão tributária no Judiciário, para que as desistências de duas execuções fiscais se efetivassem, retornando à garantia da execução fiscal no proveito econômico, valor do bem, em cerca de 1,5 milhão de reais.

Os formalismos tradicionais da execução fiscal, portanto, não fazem o contribuinte adimplir mais as suas obrigações tributárias, mas ao contrário, causam efeito reverso com o excesso burocrático e ausência de diálogo entre as partes. É necessário, diante disso, avaliar o custo de uma política pública para o Estado de acordo com os recursos dispendidos e o resultado econômico alcançado, como possível análise da eficiência da execução fiscal.

Deve-se ponderar, ainda, a arrecadação de tributos como atividade financeira, no contexto das políticas públicas, cujo financiamento é elemento basilar da execução de políticas públicas voltadas a concretização da dignidade da pessoa humana.

\footnotetext{
${ }^{30}$ PGFN em Números 2020; ano-base 2019/Procuradoria Geral da Fazenda Nacional - Brasília: PGFN, 2020, p. 6.

${ }^{31}$ PGFN em Números 2020; ano-base 2019/Procuradoria Geral da Fazenda Nacional - Brasília: PGFN, 2020, p. 15.
} 
Juliana Furtado ${ }^{32}$ aduz que a cobrança mais efetiva do crédito tributário ensejou mudanças de postura do fisco federal, com introdução de atos normativos que buscam garantir celeridade, inseridos em um novo modelo de cobrança do crédito. Os novos métodos para a solução de conflitos tributários são, inclusive, considerados instrumentos de sobrevivência do processo tributário, garantindo a redução de litigiosidade e aumento de eficiência ${ }^{33}$.

Desse modo, vislumbra-se o Negócio Jurídico Processual (NJP) como um dos meios de utilizar um elemento processual com finalidade do sistema multiportas, valorizando o crédito público de forma eficiente e que supere a ultrapassada concepção dos limites da indisponibilidade do interesse público como empecilho.

O objetivo a ser buscado é a eficiência instrumental (custos econômicos da execução fiscal) e não a satisfação à risca da Lei de Execuções Fiscais. Além disso, utilizar tal mecanismo é zelar pela capacidade do contribuinte de pagamento individualizado.

Sendo assim, considerando a morosidade sistêmica da execução fiscal e os custos para o seu rito formal, utilizar mecanismos de consensualidade possui o condão de aumentar a segurança jurídica na relação fisco e contribuinte, de forma a contribuir com o avanço arrecadatório e o alcance do acesso à justiça fiscal.

Considera-se, portanto, que a consensualidade não é só uma benevolência do administrador, mas, sim, um dever de atuação, conforme os postulados constitucionais de acesso à justiça e à eficiência instrumental econômica.

\section{INSTRUMENTALIZAÇÃO DO ARTIGO 190 DO CÓDIGO DE PROCESSO CIVIL EM SEDE DE EXECUÇÃO FISCAL}

Compreendidos os aspectos teóricos que fundamentam o artigo, cabe agora adentrar especificamente ao estudo do NJP, abarcado pelo artigo 190 do Código de Processo Civil (CPC) e pelas portarias da Procuradoria Geral da Fazenda Nacional (PGFN) $n^{\circ} 360$ de

\footnotetext{
32 ARAÚJO, Juliana Furtado Costa. A Efetividade da Cobrança do Crédito Tributário Federal como Fundamento Legitimador da Portaria PGFN 33/28. In: Juliana Furtado Costa Araujo, Paulo Cesar Conrado (Coord.). Inovações na cobrança do crédito tributário, São Paulo: RT Thomson Reuters. 2019, p. 11.

${ }^{33}$ NETO, Daniel; AUGUSTO, Carlos; RIBEIRO, Diego Diniz. Meios alternativos de composição de conflitos e sua incidência no âmbito da persecução do crédito tributário. In: Juliana Furtado Costa Araujo, Paulo Cesar Conrado (Coord.). Inovações na cobrança do crédito tributário, São Paulo: RT Thomson Reuters. 2019, p. $176-188$.
} 
13/06/2018 e n 742 de 21/12/2018, no âmbito da execução fiscal de débitos inscritos na dívida ativa da União.

As supracitadas Portarias da Procuradoria Geral da Fazenda Nacional são marcos legais no diálogo com o contribuinte, pois possibilitaram, após intensas discussões sobre a indisponibilidade do crédito público, a negociação com o contribuinte em sede de execução fiscal. Tal mecanismo permitiu a negociação de atos do processo, além de, inclusive, possibilitar a realização de planos de liquidação do crédito.

Conforme se extrai do site da $\mathrm{PGFN}^{34}$, o negócio jurídico processual é "o instrumento através do qual o devedor negocia com a PGFN, diretamente, sobre as formas disponíveis para quitação de seus débitos inscritos em dívida ativa da União ou do FGTS"35.

De fato, customizou-se o rito previsto na Lei de Execução Fiscal para abranger a legalidade de acordo com a particularidade do processo e do contribuinte. Aliás, não haveria como realizar negócio jurídico processual sem utilizar instrumentos acessórios, como plano de amortização, mesmo que muitos aleguem que se trate de negócio jurídico impróprio, conceituação que não interfere no objetivo final da política tributária, qual seja, a arrecadação de recursos.

O negócio jurídico, na perspectiva da Portaria PGFN nº 33/2018, não é determinado por seu objeto, senão por sua finalidade, qual seja, incrementar a recuperação dos débitos em tempo razoável no processo de execução ${ }^{36}$. Tem-se, portanto, o NJP como instrumento da política pública tributária ${ }^{37}$.

Ademais, a portaria da PGFN estabelece rol não exaustivo, tendo em vista que a negociação pode ocorrer de forma individual e de acordo com o interesse fazendário, dado que o fisco analisará o histórico fiscal do devedor, parcelamentos anteriores, possíveis fraudes, análise de garantias e de execuções fiscais. Há, pois, controle de legalidade do ato,

\footnotetext{
34 Vide endereço eletrônico: https://www.gov.br/pgfn/pt-br/servicos/orientacoes-contribuintes/negociojuridico-processual

${ }^{35}$ Convém citar que a negociação com o contribuinte poderá versar sobre calendarização da execução fiscal; criação de plano de amortização; aceitação, avaliação, substituição e liberação de garantias; e modo de constrição ou alienação de bens - rol não exaustivo.

${ }^{36}$ CONRADO, Paulo Cesar. Negócio jurídico processual em matéria tributária e as Portarias PGFN 33/2018 (art. 38) e 360/2018 (alterada pela 515/2018). In: ARAUJO, Juliana Furtado Costa; CONRADO, Paulo Cesar (Coord.). Inovações na cobrança do crédito tributário. São Paulo: RT Thomson Reuters, 2019, p. 197.

${ }^{37}$ Política conceituada como atividade estatal desenvolvida com a finalidade de arrecadar recursos aos cofres públicos, por meio de instrumentos e programas de arrecadação fiscal (MENEZES, Daniel Telles. Política tributária como política pública. Análise do sistema tributário pela tipologia de Theodore Lowi. Revista PGFN, ano 7, n. 10, 2017, p. 116).
} 
tendo em vista que a motivação da negociação deve ser realizada pelo Procurador da Fazenda de forma exaustiva.

Nota-se, portanto, que utilizar o NJP é zelar pela capacidade do contribuinte de pagamento individualizado, sem renunciar o crédito tributário. Cumpre observar que o NJP pode ser rescindido em hipóteses de seu descumprimento, o que ensejará a execução das garantias prestadas e a retomada da cobrança do crédito.

Antônio do Passo Cabral ${ }^{38}$ aduz que os negócios jurídicos possuem autonomia em relação ao direito material, mas não são abstratos, como se ignorassem o direito material, dado que o direito substancial impacta nos requisitos de validade dos acordos sobre o processo e também os seus limites, uma vez que não é possível que um pacto processual resulte em algo vedado pelo direito material. No entanto, para o autor, a regra é a independência das convenções processuais em relação ao direito material.

O processo civil contemporâneo fixou a premissa máxima de in dubio pro libertate, que é uma pressuposição em favor da liberdade de conformação do procedimento, de acordo com a vontade das partes ${ }^{39}$.

Ademais, o CNJ, ao editar a Resolução n 261/2018, criou a "Política e o Sistema de Solução Digital da Dívida Ativa", cujo escopo é melhorar a composição entre o contribuinte e a Fazenda Pública ${ }^{40}$, observando a eficiência da execução e à razoável duração do processo. Assim, tal sistema visa disseminar a cultura de pacificação social, observando planejamento de acordos que respeitem o interesse público, conforme artigo $2^{\circ}$ da Resolução ${ }^{41}$.

Nesse contexto, as medidas consensuais em âmbito tributário se tornaram uma ferramenta apta a produzir resultados quanto aos índices de recuperação dos créditos tributários, além de contribuir com a eficiência do Poder Judiciário.

\footnotetext{
${ }^{38}$ CABRAL, Antônio do Passo. Convenções processuais. Salvador: JusPodivm, 2020, p. 309.

${ }^{39}$ CABRAL, Antônio do Passo. Convenções processuais. Salvador: JusPodivm, 2020, p. 312.

${ }^{40}$ Insta trazer à baila o objetivo da criação de tal sistema: Art. $4^{\circ}$ Compete ao CNJ desenvolver o Sistema de Solução Digital da Dívida Ativa com o objetivo de estimular e facilitar o acordo entre as partes, incentivando a pacificação social e a redução dos litígios fiscais, ampliando a probabilidade de recebimento de dívidas consideradas irrecuperáveis.

41 Art. $2^{\circ} \mathrm{Na}$ implementação do Sistema de Solução Digital da Dívida Ativa, com vistas à boa qualidade dos serviços e à disseminação da cultura de pacificação social, serão observados: I - a eficiência do atual sistema de execução fiscal; II - o volume de dívidas ativas que permanecem estacionárias nas fazendas públicas; III o montante das dívidas ativas que prescrevem e caracterizam remissão involuntária de créditos tributários e não tributários; IV - a necessidade de planejamento com base em probabilidades para a definição de acordos que respeitem os princípios da moralidade, da probidade administrativa e do interesse público.
} 
Posto isso, conforme dados disponibilizados pelo Gabinete da Procuradoria Geral da Fazenda Nacional em pedido de acesso à informação no 03005.183995/2020-35, foram realizados 42 (quarenta e dois) termos de negócios jurídicos processuais em 2019 e 16 (dezesseis, dado parcial) em 2020.

A quantidade de negociações ainda é baixa, por se tratar de inovação recente, mas os valores negociados são expressivos e representam significativo avanço para a arrecadação fiscal.

Convém citar que os valores arrecadados não são passíveis de exata mensuração, pois há tipos de negócios que não envolvem obtenção de valores de imediato e apenas auxiliam o processo de execução fiscal com substituição de garantias ou calendarização da execução fiscal, o que pode facilitar o cumprimento de obrigações sem a entrada imediata de valores.

No entanto, quando os acordos envolvem plano de amortização, de forma a adequar o adimplemento ao fluxo de caixa do contribuinte, há estimativa dos valores envolvidos nos acordos. Nesse contexto, segundo informação da $\mathrm{PGFN}^{42}$, em 2019 por meio de planos de amortização e planos de garantia, estima-se que os créditos negociados alcançam o montante de cerca de $\mathrm{R} \$ 3.187 .085 .786,46$ (três bilhões, cento e oitenta e sete milhões, oitenta e cinco mil, setecentos e oitenta e seis reais e quarenta e seis centavos) e, no ano de 2020, a estimativa de negociação é de R \$ 3.801.956.715,03 (três bilhões, oitocentos e um milhões, novecentos e cinquenta e seis mil, setecentos e quinze reais e três centavos).

As vantagens da negociação são inúmeras, como: adequação do pagamento à capacidade financeira do contribuinte, recuperação de créditos antigos e com baixa probabilidade de recuperação, possibilidade de aproximação entre fisco e contribuinte, aumento da confiança legítima entre administrador e administrado, evitar a inércia com prescrição de execuções, entre outras.

Outrossim, é relevante distinguir brevemente o instituto do NJP da transação tributária em termos práticos e conceituais. Ao contrário do NJP que é um mecanismo de adequação procedimental, em que não há concessões no valor do crédito, a transação exprime ideia de realização de um pacto em torno de concessões recíprocas para extinguir o crédito tributário prevista pela Lei n ${ }^{\circ} 5.172 / 1966$, que teve eficácia com a Lei Complementar

\footnotetext{
${ }^{42}$ Dados apresentados pela PGFN em novembro de 2020, por meio de processo de solicitação de informação previsto na Lei de Acesso à Informação no 12.527/2011, registrado sob o no 03005.183995/2020-35.
} 
$n^{\circ}$ 174/2020. Ambos os mecanismos de consensualidade representam avanço na relação entre fisco e contribuinte, mas são sujeitos a critérios distintos de conveniência da Administração.

Compreende-se que a eternização de conflitos não é interessante para nenhum dos lados. Logo, a atuação negocial da PGFN foca em concentrar no que ainda não está resolvido e, por consequência, tentar reduzir as altas taxas de congestionamento das execuções fiscais no Judiciário brasileiro. Posto isso, não se justifica uma execução fiscal durar cerca de oito anos, conforme estudo do IPEA ${ }^{43}$ e, nesse período, por muitas vezes, ter gerado mais gastos do montante do crédito arrecadado ou até mesmo serem atingidas pela prescrição ${ }^{44}$.

A solução negociada dos litígios é um "importante e poderoso instrumento para a efetivação da tutela dos direitos difusos e coletivos, que prescinde do longo e tortuoso processo judicial” ${ }^{45}$. Além disso, reduz custos e antecipa à sociedade os benefícios e o usufruto dos direitos fundamentais.

No intuito de aprimorar o consenso e reduzir o número de demandas judiciais, o CPC primou pela consensualidade como forma de solucionar conflitos. Dessa forma, é indispensável a utilização de procedimentos dialógicos já previstos no ordenamento jurídico brasileiro, com o objetivo de ser uma forma de pacificação social legítima, estável, eficiente e transparente.

\section{CONSIDERAÇÕES FINAIS}

Em síntese, sugere-se que os agentes públicos nas searas tributárias estadual e municipal sigam o exemplo pioneiro e exitoso da Procuradoria Geral da Fazenda Nacional de possibilitar o efetivo diálogo com o contribuinte, no tocante a desconstrução de um ambiente de batalha judicial interminável e oneroso às partes e, principalmente, em prol do deslinde final da lide com a arrecadação tributária necessária.

\footnotetext{
${ }^{43}$ BRASIL. Instituto de Pesquisa Econômica Aplicada (IPEA). Gestão e jurisdição: o caso da execução fiscal da União. Organizadores: Alexandre dos Santos Cunha, Paulo Eduardo Alves da Silva. - Brasília: Ipea, 2013, p. 278. Disponível em: http://repositorio.ipea.gov.br/handle/11058/988. Acesso em 18 mar. 2021.

${ }^{44} \mathrm{O}$ custo médio de uma execução é $\mathrm{R} \$ 4.368,00$ (em relação a remuneração dos servidores envolvidos no processamento da execução fiscal). (IPEA, 2011, p. 32). Além disso, os dados do IPEA apontam que 27,7\% dos casos de execução fiscal são atingidos pela prescrição e $17 \%$ pelo cancelamento da dívida.

${ }^{45}$ BADIN, Arthur Sanchez. Conselho Administrativo de Defesa Econômica (Cade). A transação judicial como instrumento de concretização do interesse público. Revista de Direito Administrativo, Rio de Janeiro, v. 252, setembro/dezembro 2009, p. 195.
} 
Nesses moldes, soluções consensuais de conflitos como forma de atender o acesso à ordem jurídica justa devem ser priorizadas no ordenamento brasileiro, uma vez que, assim como nos ensina Juarez de Freitas ${ }^{46}$, é necessário priorizar a resolução customizada, não adversarial e cooperativa, em lugar da perpetuação de discussões judiciais infindáveis.

Com efeito, não se espera de forma utópica e romantizada que a consensualidade seja a solução de todos os problemas da execução fiscal, mas que possa ao menos desenvolver o diálogo legítimo em tal seara como procedimento processual que conduza ao acesso à justiça e à pacificação social. Sendo que a autonomia das partes em convencionar formalidades atinentes à cobrança do débito fiscal é inserida no escopo de jurisdição e acesso à justiça.

Urge ressaltar que o artigo 190 do Código de Processo Civil, aplicado na seara tributária, é um comando normativo que possibilita não só o desafogo judicial, como também a alteração do relacionamento entre fisco e contribuinte, em observância ao dever de atuação consensual, com lastro na negociação, diálogo e cooperação.

Assim, considera-se o procedimento estabelecido pelo NJP uma possível forma de acesso à justiça e à pacificação social, além de serem notórios instrumentos de gestão, pois, além de possibilitar o deslinde da execução fiscal, permeia um ambiente consensual que possibilita recuperar recursos aos cofres públicos.

Ademais, a experiência observada por meio dos dados obtidos demonstra que execuções antes consideradas infrutíferas representam considerável aumento de arrecadação tributária após negociação dialogada com a PGFN. De igual modo, os dados referentes ao Judiciário brasileiro atestam que a relação adversarial entre fisco e contribuinte resultam em altas taxas de congestionamento judicial, gastos processuais, baixa efetividade arrecadatória, além de retratarem que a lei formal de execução fiscal não se mostra suficiente para alcançar a devida arrecadação de recursos aos cofres públicos.

No presente artigo, portanto, demonstrou-se, de forma dedutiva e por meio da observação de dados, que a gestão fiscal dos créditos tributários pautada na consensualidade tem o condão de apresentar resultados frutíferos para a arrecadação fiscal, resultando em efetivo acesso à justiça com o término da lide em tempo razoável e por meios adequados.

\footnotetext{
${ }^{46}$ FREITAS, Juarez. Direito administrativo não adversarial: a prioritária solução consensual de conflitos. RDA - Revista de Direito Administrativo, Rio de Janeiro, v. 276, p. 25-46, set./dez. 2017, p. 35.
} 


\section{REFERÊNCIAS:}

ALMEIDA, Fernando Menezes de. A noção constitucional de "administração pública" aplicada ao Poder Judiciário. In: CONTI, José Maurício (Coord.). Poder Judiciário: orçamento, gestão e políticas públicas. 1. ed. São Paulo: Almedina, 2017. p.17-28.

ARAÚJO, Juliana Furtado Costa. A Efetividade da Cobrança do Crédito Tributário Federal como Fundamento Legitimador da Portaria PGFN 33/28. In: Juliana Furtado Costa Araujo, Paulo Cesar Conrado (Coord.). Inovações na cobrança do crédito tributário, São Paulo: RT Thomson Reuters. 2019.

AVELINO, Murilo Teixeira. A regulação dos negócios jurídicos processuais pela Fazenda Nacional. Civil Procedure Review, v. 11, n. 2: mai.-ago. 2020, p. 160.

ÁVILA, Humberto. Repensando o "princípio da supremacia do interesse público sobre o particular". In: SARLET, Ingo Wolfgang. O direito público em tempos de crise: estudos em homenagem Ruy Ruben Ruschel. Porto Alegre: Livraria do Advogado, 1999.

BACELLAR FILHO, Romeu Felipe. Parecer Administração Tributária. In: Análise dos dispositivos constitucionais da nova Administração tributária. Brasília: Fenafisco, 2008 .

BADIN, Arthur Sanchez. Conselho Administrativo de Defesa Econômica (Cade). A transação judicial como instrumento de concretização do interesse público. Revista de Direito Administrativo, Rio de Janeiro, v. 252, p. 189-217, setembro/dezembro 2009.

BATISTA JÚNIOR, Onofre Alves; CAMPOS, Sarah. A administração pública consensual na modernidade líquida. Fórum Administrativo, Belo Horizonte, v. 14, n. 155, jan. 2014.

OLIVEIRA, Gustavo Justino; SCHWANKA, Cristiane. A Administração Consensual como nova face da Administração Pública no Séc. XXI: fundamentos dogmáticos, formas de expressão e instrumentos de ação. Revista da Faculdade de Direito da Universidade de São Paulo, v. 104, jan./dez. 2009.

BINENBOJM, Gustavo. A consensualidade administrativa como técnica juridicamente adequada de gestão eficiente de interesses sociais. Revista Eletrônica da 
Procuradoria Geral do Estado do Rio de Janeiro - PGE-RJ, Rio de Janeiro, v. 3 n. 3, set./dez. 2020.

BINENBOJM, Gustavo. Da supremacia do interesse público e dever de proporcionalidade: um novo paradigma para o Direito Administrativo. In: SARMENTO, Daniel. Interesses públicos versus interesses privados: desconstruindo o princípio de supremacia do interesse público. Rio de Janeiro: Lumen Juris, 2007.

BOURGES, Fernanda Schuhli. Administração Pública dialógica: em busca da concretização isonômica de direitos fundamentais sociais. Revista Eurolatinoamericana de Derecho Administrativo, Santa Fe, v. 5, n. 1, p. 29-53, jan. /jun. 2018.

BRASIL. Código de Processo Civil. Lei n. ${ }^{\circ} 13.105$, de 16 de março de 2015. Disponível em: https://presrepublica.jusbrasil.com.br/legislacao/174276278/lei-13105-15. Acesso em: 25 ago. 2020.

BRASIL. Instituto de Pesquisa Econômica Aplicada (IPEA). Comunicado do IPEA $n^{\circ} 127$. Disponível em: http://www.ipea.gov.br/portal/index.php?opition=com_content\&view=article\&id=12794. Acesso em: 25 ago. 2020.

BRASIL. Instituto de Pesquisa Econômica Aplicada (IPEA). Gestão e jurisdição: o caso da execução fiscal da União. Organizadores: Alexandre dos Santos Cunha, Paulo Eduardo Alves da Silva. - Brasília: Ipea, 2013. Disponível em: http://repositorio.ipea.gov.br/handle/11058/988. Acesso em 18 mar. 2021.

BRASIL. Superior Tribunal de Justiça. Embargos em Recurso Especial $n^{\circ}$ 1.345.613/SC Santa Catarina. Relator Ministro Napoleão Nunes Maia Filho. Acordo aos 26/06/2019.

BRESSER-PEREIRA, Luís Carlos. Reforma gerencial e legitimação do estado social. Revista de Administração Pública, Rio de Janeiro, v. 51, n. 1, p. 147-156, jan./fev. 2017.

BUÍSSA, Leonardo; BEVILACQUA, Lucas. Consensualidade na administração pública e transação tributária. Fórum Administrativo, Belo Horizonte, v. 15, n. 174, p. 46-54, ago. 2015.

CABRAL, Antônio do Passo. Convenções processuais. Salvador: JusPodivm, 2020, p. 215.

CABRAL, Antônio do passo; CUNHA, Leonardo Carneiro da. Negociação Direta ou resolução colaborativa de disputas (Collaborative Law): “mediação sem mediador". 
In: Justiça Multiportas: mediação, conciliação, arbitragem e outros meios de solução adequada para conflitos. Ed. Juspodvim, Salvador, 2016.

CAPPELlETTI, M.; GARTH, B. Acesso à justiça. Tradução Ellen Gracie Northfleet. Porto Alegre: Frabis, 1988.

CONRADO, Paulo Cesar. Negócio jurídico processual em matéria tributária e as Portarias PGFN 33/2018 (art. 38) e 360/2018 (alterada pela 515/2018). In: ARAUJO, Juliana Furtado Costa; CONRADO, Paulo Cesar (Coord.). Inovações na cobrança do crédito tributário. São Paulo: RT Thomson Reuters, 2019.

CONSELHO NACIONAL DE JUSTIÇA. Justiça em Números 2020; ano-base 2019/Conselho Nacional de Justiça. Brasília: CNJ, 2020.

FERRAZ, Luciano. Controle e consensualidade: fundamentos para o controle consensual da Administração Pública (TAG, TAC, SUSPAD, acordos de leniência, acordos substitutivos e instrumentos afins). 2. ed. Belo Horizonte: Fórum,2020. p.207-233.

FREITAS, Juarez. Direito administrativo não adversarial: a prioritária solução consensual de conflitos. RDA - Revista de Direito Administrativo, Rio de Janeiro, v. 276, p. 25 46, set./dez. 2017.

FREITAS, Juarez. Direito fundamental à boa administração pública. 3. ed. São Paulo: Malheiros, 2014.

GRINOVER, Ada Pellegrin. Ensaio sobre a processualidade: fundamentos para uma nova teoria geral do processo. Brasília: Gazeta Jurídica, 2016.

JUSTEN, Marçal. Conceito de interesse público e a "Personalização" do Direito Administrativo. Revista Trimestral de Direito Público. São Paulo: Malheiros, 1999. p. 115-136.

MARTINS, Ana Paula Antunes. COLARES. Elisa Sardão. "Fordismo Judiciário". A administração do judiciário no brasil e os impactos nos processos de execução físcal. In: CUNHA, Alexandre dos Santos; SILVA, Paulo Eduardo Alves da (Org.). Gestão e Jurisdição: o caso da execução fiscal da União. Brasília: IPEA, 2013.

MENEZES, Daniel Telles. Política tributária como política pública. Análise do sistema tributário pela tipologia de Theodore Lowi. Revista PGFN, ano 7, n. 10, 2017. Disponível em: https://www.gov.br/pgfn/pt-br/central-deconteudo/publicacoes/revista-pgfn/ano-vii-numero-10-2017/10politica.pdf. Acesso em: $16 \mathrm{dez}, 2020$. 
MOREIRA NETO. Mutações do Direito Público. Rio de Janeiro: Renovar, 2006. p. 57-108. (Novas tendências da democracia...; Direitos humanos, legitimidade e constitucionalismo).

NETO, Daniel; AUGUSTO, Carlos; RIBEIRO, Diego Diniz. Meios alternativos de composição de conflitos e sua incidência no âmbito da persecução do crédito tributário. In: ARAUJO, Juliana Furtado Costa; CONRADO, Paulo Cesar (Coord.). Inovações na cobrança do crédito tributário. São Paulo: RT Thomson Reuters, 2019.

PGFN em Números 2020; ano-base 2019/Procuradoria Geral da Fazenda Nacional Brasília: PGFN, 2020.

PGFN. Portaria $n^{\circ}$ 360, de 13 de junho de 2018. Autoriza a realização, no âmbito da Procuradoria Geral da Fazenda Nacional, de modalidades específicas de negócio jurídico processual, inclusive calendarização.

PGFN. Portaria $n^{\circ}$ 742, de 21 de dezembro de 2018. Disciplina, nos termos do art. 190 da Lei $\mathrm{n}^{\mathrm{o}} 13.105$, de 16 de março de 2015, a celebração de negócio jurídico processual - NJP em sede de execução fiscal, para fins de equacionamento de débitos inscritos em dívida ativa da União, e dá outras providências.

RIBEIRO, Mária de Fátima; CASTRO, Aldo Aranha de. Políticas Públicas Tributárias, Desenvolvimento e Crise Econômica. Publica Direito. Disponível em: http://www.publicadireito.com.br/artigos/?cod=dc6a6489640ca02b. Acesso em: 25 ago. 2019.

SANTOS, Boaventura de Sousa. Para uma revolução democrática da justiça. 3. ed. São Paulo: Cortez, 2011.

SILVA, Rogerio Nery da. Políticas Públicas e Administração Democrática. Sequência: Estudos Jurídicos e Políticos, Florianópolis, p. 57-84, jul. 2012.

SPADONI, Lila. Psicologia realmente aplicada ao direito. 2. ed. São Paulo: LTr, 2016.

TORRES, Ricardo Lobo. Mutações do Estado Fiscal. In: OSÓRIO, Fábio Medina; SOUTO, Marcos Juruena Villela (Coord.). Direito administrativo: estudos em homenagem a Diogo de Figueiredo Moreira Neto. Rio de Janeiro: Lumen Iuris, 2006.

WATANABE, Kazuo. Política Pública do Poder Judiciário Nacional para tratamento adequado dos conflitos de interesses. Revista de Processo (RePro), São Paulo, ano 136, v. 195, maio 2011. 